\title{
Exploitation of junior scientists must end
}

Sir - There has been a longstanding need for serious analysis of the genuine ethical problems of exploitation, corruption and abuse in science ${ }^{1}$. Unfortunately, the debate instead tends to be framed in terms of 'fabrication, falsification and plagiarism'.

On the one hand, we have seen intense and minute public scrutiny of whether a few individuals may have presented false or misleading scientific information; and on the other, independent juries have confirmed that research has been stolen and that corruption has occurred at universities ${ }^{2,3}$. Most horrifying of all, Jason Altom, a promising graduate student, felt so pressured and trapped by academic "abuse" at Harvard that he took his life ${ }^{4}$.

So we have an elite society that exploits junior colleagues to the point of suicide, but we are choosing to discuss not what is fundamentally wrong with the system, but whether the system produces accurate information at all times.

Two important points about scientific ethics have not, to my knowledge, been discussed together. First, scientific falsification is both rare and severely punished. This is intrinsic to the nature of science: a falsification that has any meaningful implications will sooner or later be found out as its implications are examined. Likewise scientists are understandably fiercely protective of the perceived value of their product, so punishment for falsification is severe.
Second, exploitation of junior scientists by their seniors has arguably become commonplace, but is rarely discouraged on the contrary, scientists who exploit their juniors are richly rewarded.

There is considerable anecdotal evidence for these views. For example, a researcher at a large private university was reportedly berated and then struck in the face by her academic supervisor when, after working without pay for two years, she requested a salary. The senior professor in charge of the laboratory then fired the researcher in response to a court judgement against the supervisor ${ }^{5}$.

In another example, according to independent sources, senior professors at different universities routinely hire foreign postdocs who have to work indefinitely under conditions that they stipulate by refusing to write letters of recommendation.

And in a third example, the chairperson of a university department has been accused of changing the budgets on grants written by junior researchers to support himself rather than the grant authors. $\mathrm{He}$ then allegedly stopped their salaries without notice and demanded that the researchers ghost-write further grant proposals as the price for reinstatement.

The atmosphere that would permit a professor to think that such behaviour could be acceptable seems to be clear evidence that the system is badly broken. Nor are these incidents obscure. On the contrary, the first case was reported in campus and city newspapers, and the last was reported at the time to university officials at the highest level. No action was taken against any of the senior faculty members involved. In each case he remains in good official standing.

The strictures against open confrontation of offenders are also well known. A certain method of ending an academic career is to protest openly against mistreatment - however clear the evidence or egregious the offence.

Discussing, in this atmosphere, whether or not fabrication, falsification or plagiarism may occur seems to me like asking whether employees in a company accused of being a sweatshop pilfer thread or make shoddy clothes. It is time for scientists of merit to address the real issues of concern to the next generation of scientists.

Are incidents such as those I report common? Can responsible scientists take measures to protect students and junior researchers? These are the issues crying out for attention, not whether data has ever been pilfered or if research might be shoddy. Troy Shinbrot

Department of Chemical \& Biochemical

Engineering, Rutgers University,

Piscataway, New Jersey 08854, USA

1. Abbott, A. et al. Nature 398, 13-17 (1999).

2. Charatan, F. B. Br. Med. J. 315, 501 (1997).

3. Science 265, 463 (1994).

. Nadis, S. Nature 395, 826 (1998).

5. Zorn, E. “Chicagoland” p. 1, Chicago Tribune (25 Feb. 1993).

\section{Lifting the lid on the}

\section{homeobox discovery}

Sir - In reviewing my book, Master

Control Genes in Development and Evolution, William McGinnis and Peter A. Lawrence $^{1}$ invoke Lewis Carroll's remark that "your view depends on where you're standing". The remark is only witty if the facts are correct. In this review, they are not.

Like many a discovery, that of the homeobox was sparked by a vague indication that could either be disregarded as irrelevant, or followed up. This was a weak band on a gel of Richard Garber's which most members of my research group considered to be an artefact, but to me this was the first sign of the homeobox. The reviewers claim that "[this band] was attributed to overloading of the gel, lumped into the 'uninterpretable results' category and not followed up". This statement is incorrect. We reproduced this band and documented it in two papers.
The finding of this cross-hybridizing band was first published in Garber's paper': "Under stringent hybridization conditions, weak homology with both the 903 and 909 probes was detected at position $190 \mathrm{~kb}$... These findings are being investigated further"; and subsequently in McGinnis's paper $^{3}$ describing the discovery of the homeobox: "Garber et al. found a weak homology between the 903 cDNA and a site to the left of the Antp locus at position 190 on the map in Fig. 1. This site has subsequently been shown to be part of the transcription unit of the fushi tarazu gene (A. K. and E. H. in preparation)".

Would we have published this finding if I had judged it an artefact "lumped into uninterpretable results"? In fact, it was the first sign of the homeobox that caused me great excitement. It was McGinnis who analysed this weak homology cleanly and determined the sequence of the homeobox. Because of his important contribution, he fully deserved to be first author of the paper describing the homeobox. Michael Levine, Atsushi Kuroiwa and Ernst Hafen were additional key contributors to this important discovery. Why is it so hard for McGinnis and Lawrence to accept that I, too, may have had a share in it?

Walter Gehring

Biozentrum, University of Basel,

Klingelbergstrasse 70, CH-4056 Basel, Switzerland

McGinnis and Lawrence reply - Gehring states that there is documentary evidence that it was he alone of his research group who appreciated that a weak band on Garber's Southern blot of autumn 1982 was the first sign of the homeobox. This evidence consists of the statement in the November 1983 paper of Garber et al. ${ }^{2}$ that "weak homology was detected between 903 and 909 probes (Antennapedia cDNAs) and position 190 (of the genomic walk that included the Antennapedia transcription unit)". However, this paper was submitted on 18 July 1983, after the significance of the homeobox cross-hybridization had become clear to everyone in Gehring's lab — but by the different route described in our review.

In July 1983, the status of homeobox 
research was as follows. A few novel Drosophila homeobox clones had been isolated, and one of these was defined as a $3^{\prime}$ exon of the Ultrabithorax (homeotic) gene. All the novel clones mapped to cytogenetic regions that were known to contain the two homeotic gene clusters in flies. The transcripts encoded in these clones were expressed in unique, homeotic-like stripes on the anteroposterior axis of developing embryos. So, at the time the 1983 Garber paper was written, it was known in Gehring's lab (but only retrospectively) that Garber's band was not an artefact.

It is always possible that Gehring sensed or knew in 1982 that Garber's band was a crucial clue which should be the basis of further investigation. However, to our knowledge no one heard any such suggestion, nothing was done about it, and it did not spark the crucial experiments on the homeobox sequence in Antennapedia and other developmental control genes.

\section{William McGinnis}

Department of Biology 0349, University of California, San Diego, 9500 Gilman Drive, La Jolla, California 92093-0349, USA

\section{Peter Lawrence}

Medical Research Council Laboratory of Molecular

Biology, Hills Road, Cambridge CB2 2QH, UK

1. McGinnis, W. \& Lawrence, P. A. Nature 398, 301-302 (1999).

2. Garber, R., Kuroiwa, A. \& Gehring, W. J. EMBO J. 2, 2027-2036 (1983)

3. McGinnis, W., Levine, M. S., Hafen, E., Kuroiwa, A. \& Gehring, W. J. Nature 308, 428-433 (1984).

\section{Longevity - does}

\section{family size matter?}

\section{Sir - Rudi Westendorp and Thomas} Kirkwood ${ }^{1}$ conclude that women who live longer have fewer children. This can be ascribed almost entirely to an increase in the proportion of childless women in higher age groups. For those women that have children, the mean number of children increases gradually, with a maximum in the 71-80-year-old group, followed by a slight downward trend which is not significant (Table 1).

The overrepresentation of childless women in high age groups suggests that giving birth and raising children shortens life expectancy. But, once you have children, the number you have makes no difference to your life expectancy. Therefore, it is not a matter of reduced fertility, but a case of 'to have or have not'.

\section{Toon Ligtenberg, Henk Brand}

Department of Oral Biology, Academic Centre for

Dentistry, van der Boechorststraat 7 ,

1081 BT Amsterdam, The Netherlands

Westendorp and Kirkwood reply - We found that aristocratic women had low average family sizes, the reasons for which are discussed by Jim Cummins ${ }^{2}$. In these circumstances, any impairment of fertility is likely to result in an increased likelihood of remaining childless. Excluding childless couples from the analysis is therefore counterintuitive. In our opinion, the data from the British aristocracy do not support Ligtenberg and Brand's conclusion that "once you have children, the number you have makes no difference to your life expectancy".

A study $^{3}$ of 822,593 women from the Norwegian census of 1970 found that, among post-menopausal women, those with larger numbers of children (more than four) also had higher mortality rates. This is consistent with our finding of a negative association between longevity and reproductive success; furthermore, it suggests that family size does matter.

In his News and Views article about our paper, Daniel Promislow ${ }^{4}$ suggested that environmental, rather than genetic, factors might explain the trade-off between longevity and reproductive success, which we showed was similar for women and for men. For example, a large family might increase environmental stress and mortality risk for both parents. If this was the case, spouses' lifespans should be correlated. We found a statistically significant correlation, but it accounted for only $2 \%$ of the variance in age at death. The weakness of this correlation argues strongly against environmental factors playing a major role in the trade-off, and supports the hypothesis that genetic factors are important.

\section{R. G. J. Westendorp ${ }^{\star} \dagger$, T. B. L. Kirkwood $\dagger$}

* Section of Gerontology and Geriatrics, Department of General Internal Medicine, and Clinical

Epidemiology, Leiden University Medical Centre CO-

\begin{tabular}{|c|c|c|c|}
\hline Age at death & Proportion childless & Nu & r of children \\
\hline (years) & & mean for all women & mean for women having children \\
\hline$<20$ & 0.66 & 0.45 & 1.32 \\
\hline $21-30$ & 0.39 & 1.35 & 2.21 \\
\hline $31-40$ & 0.26 & 2.05 & 2.77 \\
\hline $41-50$ & 0.31 & 2.01 & 2.91 \\
\hline $51-60$ & 0.28 & 2.4 & 3.33 \\
\hline $61-70$ & 0.33 & 2.36 & 3.52 \\
\hline $71-80$ & 0.31 & 2.64 & 3.83 \\
\hline $81-90$ & 0.45 & 2.08 & 3.78 \\
\hline$>90$ & 0.49 & 1.80 & 3.53 \\
\hline
\end{tabular}

P, PO Box 9600, 2300 RC Leiden, The Netherlands $\dagger$ Biological Gerontology Group, Department of Geriatric Medicine and The School of Biological Sciences, University of Manchester, 3.239 Stopford Building, Oxford Road, Manchester M13 9PT, UK

1. Westendorp, R. G. J. \& Kirkwood, T. B. L. Nature 396, 743-746 (1998).

2. Cummins, J. Nature 397, 557-558 (1999).

3. Lund, E., Arnesen, E. \& Borgan, J.-K. J. Epidemiol. Community Health 44, 237-240 (1990).

4. Promislow, D. E. L. Nature 396, 719-720 (1998).

City dwellers must share blame on biodiversity

Sir - In your editorial on the debate over genetically modified foods, you say "the steady reduction of biodiversity remains a silent witness to the potential of modern agriculture to inflict damage on the environment and the wildlife it supports" (Nature 398, 639; 1999). It is unfair to attribute solely and without qualification to agriculture an effect that is correlated with a whole raft of land-use changes and also with climate change.

Many farmers take great care over the countryside. You can also argue that city dwellers contribute to the reduction in biodiversity by demanding more housing development, more motorways, and so on. A. J. Murdoch

Department of Agriculture, University of Reading, Earley Gate, PO Box 236, Reading RG6 6AT, UK

\section{Biblical answer to}

\section{cooking up pi}

Sir - In the News story about scientists' response to creationists, the scientists "comment that the Bible says that $\pi$ is 3 , not 3.14” (Nature 398, 453; 1999).

The biblical verse quoted (1 Kings 7:23) reads in part: “...measuring 10 cubits from rim to rim... It took a line of of 30 cubits to measure around it". Indeed, 30/10 equals 3, but further on in verse 26 it says: "It was a handbreadth in thickness.... Assuming that a cubit measured 18 inches and a handbreadth 3 inches, the inner diameter of the bowl would be 174 inches $(10 \times 18$ $-2 \times 3)$, and the inner circumference would be 540 inches $(30 \times 18)$. This yields a value for $\pi$ of $540 / 174$ or 3.10 . This is about a 1 per cent error from the typical value for $\pi$ of 3.14. Although we do not know the exact length of a cubit or a handbreadth, this result is very close to the actual value of $\pi$.

\section{Kevin Peil}

Reactor Engineering Group, Dow Chemical

Company, Midland, Michigan 48674, USA 